\title{
Knowledge, Attitudes, and Perceptions of Nurse Practitioners about Antibiotic Stewardship
}

Robert M. Hamilton

Brigham Young University

Follow this and additional works at: https://scholarsarchive.byu.edu/etd

Part of the Nursing Commons

\section{BYU ScholarsArchive Citation}

Hamilton, Robert M., "Knowledge, Attitudes, and Perceptions of Nurse Practitioners about Antibiotic Stewardship" (2019). Theses and Dissertations. 8550.

https://scholarsarchive.byu.edu/etd/8550

This Thesis is brought to you for free and open access by BYU ScholarsArchive. It has been accepted for inclusion in Theses and Dissertations by an authorized administrator of BYU ScholarsArchive. For more information, please contact ellen_amatangelo@byu.edu. 
Knowledge, Attitudes, and Perceptions of Nurse Practitioners

About Antibiotic Stewardship

Robert M. Hamilton

A thesis submitted to the faculty of

Brigham Young University

in partial fulfillment of the requirements for the degree of

Master of Science

Katreena C. Merrill, Chair

Karlen E. Luthy

Craig Nuttall

College of Nursing

Brigham Young University

Copyright (C 2019 Robert M. Hamilton

All Rights Reserved 


\author{
ABSTRACT \\ Knowledge, Attitudes, and Perceptions of Nurse Practitioners \\ About Antibiotic Stewardship \\ Robert M. Hamilton
College of Nursing, BYU
Master of Science
}

Background: Antibiotic stewardship (ABS) is a set of strategies to optimize the use of antibiotics with the goal of reducing antibiotic resistance, improving patient outcomes and decreasing unnecessary costs. ABS affects all venues of patient care, including outpatient, inpatient, and long-term care. While many strategies for ABS exist and best practice continues to evolve, successful ABS programs utilize a multidisciplinary approach. Nurse practitioners (NPs) play an essential role in health care education and represent a valuable potential resource for ABS efforts. The purpose of this study is to describe the knowledge, attitudes, and perceptions of NPs towards ABS.

Methods: A convenience sample of NPs attending the American Association of Nurse Practitioners annual conference was given a modified descriptive survey developed for use in a previous study conducted at a university-affiliated hospital in Florida. Descriptive statistics were used to assess normality. Chi-Square test of independence was used to test differences categorical scores by NP setting, gender, and level of education. Pearson $r$ correlation was completed to measure the relationship between age and years in practice.

Results: Two hundred NPs completed the questionnaire (88\% female; 70\% Master's degree). The range of experience was 0-45 years (mean 11 years). Most NPs worked in a private office $(23 \%)$ or community setting $(29 \%)$. Factors affecting the decisions of antibiotic prescriptions included patient condition (79\%) and patient cost (58\%). NPs in this study also based their antibiotic decisions on the antibiogram (63\%) in their setting, while $56 \%$ indicated they start with broad spectrum and tailor antibiotic choices when culture results are received. NPs reported understanding that inappropriate use of antibiotics causes resistance (97\%), harms the patient (97\%), and optimum antibiotic use will reduce resistance (94\%). Participants also recognized that strong knowledge of antibiotics was important for their job (94\%) and felt confident in their use of antibiotics (86\%). However, while $94 \%$ of respondents somewhat or strongly agreed that antibiotics are overused nationally, only $62 \%$ thought antibiotics were overused in their health care setting.

Conclusion: In this study, most NPs reported that antibiotic resistance is a problem and antibiotics are overused nationally. Fewer believe that antibiotic resistance is a problem locally and fewer still that they, personally, contribute to the problem. NPs recognize that knowledge about antibiotics is important to their career and would like more education about antibiotics and feedback about their antibiotic choices. Finding effective ways to provide this education could change practice and improve antibiotic use.

Keywords: antibiotics, antimicrobials, stewardship, resistance, nurse practitioner 


\section{TABLE OF CONTENTS}

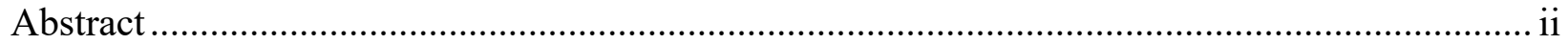

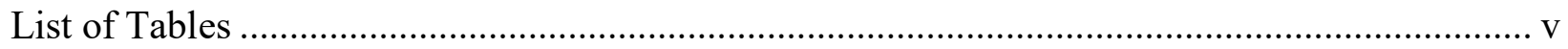

Knowledge, Attitudes, and Perceptions of Nurse Practitioners About Antibiotic Stewardship ..... 1

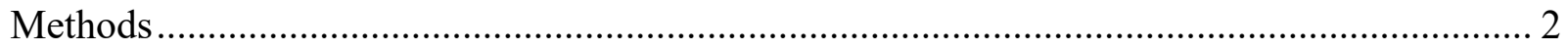

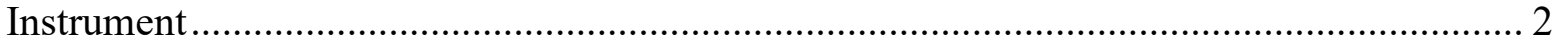

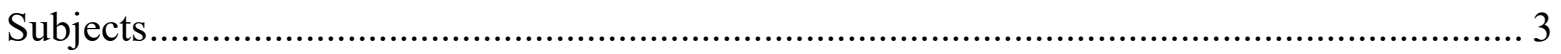

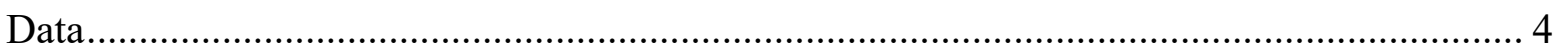

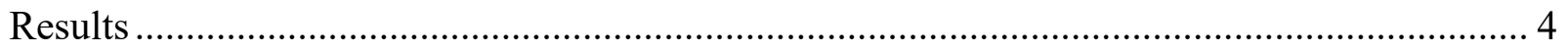

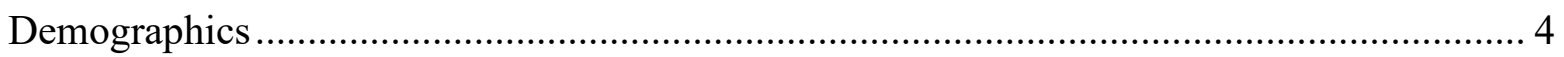

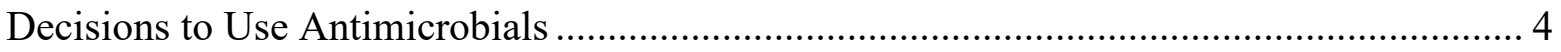

Empiric Selection of Antimicrobials ....................................................................... 5

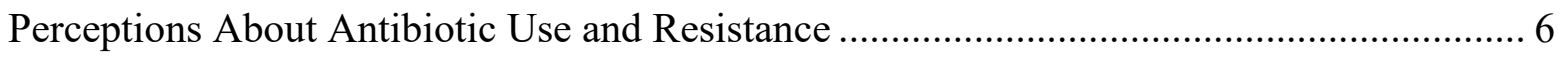

Perceptions About Continuing Education Resources .................................................... 7

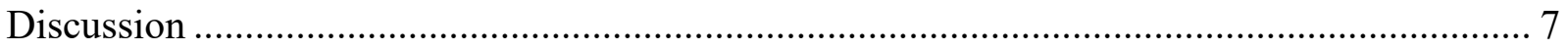

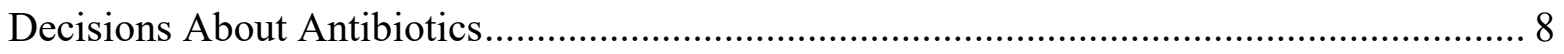

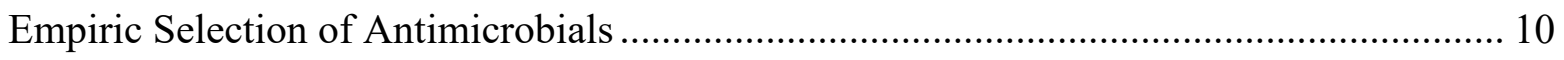

Perceptions About Antibiotic Use and Resistance .......................................................... 10

Perceptions About Continuing Education Resources ................................................. 11

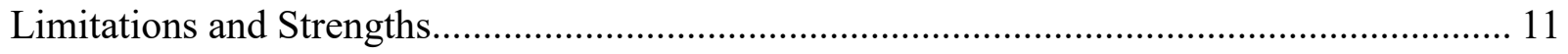




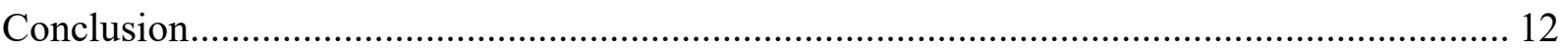

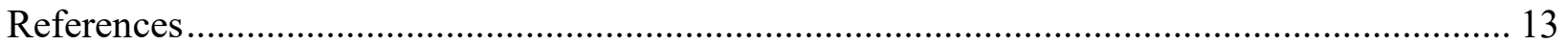

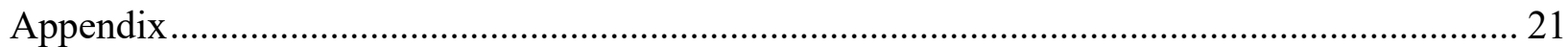




\section{LIST OF TABLES}

Table 1 Attitudes That Might Influence NP Decision to Select an Antibiotic in General......... 16

Table 2 NP Attitudes Toward the Empiric Selection of an

Antibiotic in a Patient with No Culture Information 17

Table 3 NP Perceptions About Antibiotic Use and Resistance ............................................ 18

Table 4 Frequency Distribution of NPs Perception Toward Various Educational

Resources as a Source for Continuous Education on Antibiotics 
Knowledge, Attitudes, and Perceptions of Nurse Practitioners

About Antibiotic Stewardship

Since the discovery of penicillin in 1928, antibiotics have saved countless lives. Today, growing antibiotic resistance is undermining antibiotic use in the treatment of infectious disease. The Centers for Disease Control and Prevention (CDC) estimates that every year in the United States, at least 2 million people acquire a serious infection that is resistant to one or more of the antibiotics designed to treat it, and more than 23,000 people die from these antibiotic resistant infections. Also, treatment of antibiotic resistant infections adds approximately $\$ 20$ billion in direct costs to an already burdened health care system (CDC, 2017). The worldwide statistics are even more alarming. An estimated 700,000 people die from resistant infections every year. Unless the problem of antibiotic resistance is addressed, the toll could be as high as 10 million lives and $\$ 100$ trillion in economic output by 2050 . That is the equivalent of one person every three seconds and a cost of $\$ 10,000$ for each person in the world today (O’Neill, 2016).

Overuse and misuse of antibiotics is a major cause of the increase in antibiotic resistance. In 2017, the CDC reported that approximately 269 million outpatient antibiotic prescriptions were dispensed. Given these prescription numbers, $83 \%$ of the people in the United States could receive one antibiotic prescription each year. The most critical strategy to slow the development and spread of antibiotic resistant infections is improving the prescription and use of antibiotics; a concept referred to as antibiotic stewardship (ABS) (CDC, 2017). ABS is a set of strategies to optimize the use of antibiotics to reduce antibiotic resistance, improve patient outcomes and decrease unnecessary costs.

The goal of ABS is to not only reduce the total use of antibiotics by an individual provider but to ensure that when an antibiotic is truly indicated, it is the right drug at the 
right dose, via the correct route, and for the proper duration" (Ohl \& Luther, 2014, p. 178).

Unfortunately, the CDC (2017) estimates that up to 50\% of all antibiotics prescribed are either unnecessary or are not appropriately prescribed to be effective against the disease the antibiotic was intended to treat.

ABS affects all venues of patient care, including outpatient, inpatient, and long-term care. While many strategies for ABS exist and best practice continues to evolve, successful ABS programs utilize a multidisciplinary approach. The most successful take place at the point of care. It is there that NPs, as trusted professionals, are positioned to make a difference. They are able build relationships with their patients and advocate for and provide education about their health. Nurse practitioners have the opportunity to play a key role in educating patients about antibiotic use and represent a valuable potential resource for ABS efforts. Therefore, the purpose of this study is to describe the knowledge, attitudes, and perceptions of NPs about antibiotic use, resistance, and stewardship.

\section{Methods}

\section{Instrument}

The instrument used in this study is a modified version of a questionnaire used in a study at a university-affiliated hospital in Florida (Abbo, Smith, Pereyra, Wyckoff, \& Hooton, 2012). The wording on some of items was modified to make them less hospital specific and more applicable to a broader range of practice settings. Demographic information collected included gender, number of years since graduation from NP school, specialty, and predominant practice setting (outpatient, inpatient, or both). The questionnaire used in this study consisted of 54-items measuring attitudes that influence decisions (10-items), attitudes towards empiric selection (8- 
items), perceptions about antibiotic use and resistance (23-items), and perceptions towards educational resources (13-items). Attitudes that influence decisions about antibiotics and empiric selection were scored on a 1-5 scale (never, rarely, sometimes, often, and always). The perceptions questions about antibiotic use and resistance were scored on a 5-point Likertresponse scale, from "strongly agree" to "strongly disagree." Education resources were scored on a 5-point scale, from "very useful" to "never useful."

\section{Subjects}

Following Institutional Review Board approval, a convenience sample of NPs who attended the 2018 annual American Association of Nurse Practitioners (AANP) conference in Denver, Colorado were chosen for the study. Subjects were excluded if they did not read or speak English and if they were not NPs. Subjects who wished to participate were given the option of using a tablet device on-site with the Qualtrics survey or using a link to the survey on their own device (Qualtrics, Provo, UT, 2018). Participation was voluntary, and no information was collected from those who declined to participate in the survey. Subjects were presented with an electronic implied consent form with a link to the questionnaire. The subject was allowed an unlimited time to read the implied consent form. A phone number for questions was provided in the consent. The subject was given the option to choose 'yes' or 'no' indicating their consent to participate in the study. Choosing 'yes' and proceeding with the questionnaire implied consent. Subjects who clicked 'no' were routed to a thank you page. The questionnaire took approximately 15 minutes to complete.

To protect confidentiality, the name of the subject was not obtained during the consent process. The data were downloaded and saved on the primary investigator's password protected 
laptop for data analysis. No names, IP addresses or identifiable information were collected via Qualtrics.

\section{Data}

Data were reviewed for completeness and analyzed using SPSS version 24 for analysis (IBM Corp., 2016). Descriptive statistics (Mean, SD, Skew, and Kurtosis) were performed, and each variable was assessed for normality of distribution. Percentages were calculated for categorical variables. Chi-Square test of independence was performed to detect a difference in categorical variables by gender, ethnicity and type of NP setting. A Pearson correlation statistic was completed to detect the relationship between knowledge, age, and experience. A p-value less than .05 was considered statistically significant.

\section{Results}

\section{Demographics}

Two hundred NPs completed the questionnaire. Eighty-eight percent were female, and $12 \%$ were male. The majority of the respondents (70\%) had a Master's degree, and range of experience was $0-45$ years (mean 11 years). Family NP was reported by $65 \%$ as the population for their initial NP education with 12\% indicating Adult Gerontology Primary Care NP and 9\% Adult Acute Care NP. Twenty-three percent of respondents described their current health care setting as Private Office, 18\% as Hospital/Acute Care, and 29\% as Community.

\section{Decisions to Use Antimicrobials}

Attitudes that might influence NP decisions to select an antibiotic are summarized in Table 1. Respondents agreed that treating a critically ill or immunocompromised (79\%) would 'often' or 'always' affect their decision to select an antibiotic. Fifty-eight percent of participants indicated that patient demands and expectations for antibiotics never or rarely affect their 
decision. Fifty-four percent of NPs responded that cost savings for the patient influenced their decision. The risk of missing an infection affected antibiotic selection for $44 \%$ of NPs in the study. Cost to the healthcare system influenced $30 \%$ of respondents. Open-ended comments (other) included history of past infections, co-morbidities, and clinical/institutional guidelines. There was no correlation between the decisions to use antimicrobials and the number of years in NP practice. NPs with a master's degree were more likely to prescribe antibiotics if a patient demanded antibiotics and if a patient had unexplained fever or leukocytosis than NPs with doctoral degrees $\left(X^{2}(4, \mathrm{~N}=194)=9.8, \mathrm{p}=.043\right)$ and $\left(X^{2}(4, \mathrm{~N}=194)=10.7, \mathrm{p}=.030\right)$. Caucasian NPs were more likely to consider prescribing antimicrobials for a critically ill or immunocompromised patient $\left(X^{2}(4, \mathrm{~N}=189)=14.68, \mathrm{p}=.005\right)$, while non-white NPs were more likely to prescribe antimicrobials for reassurance $\left(X^{2}(2, \mathrm{~N}=191)=5.99, \mathrm{p}=.05\right)$. There were no differences in decisions to use antimicrobials by type of NP setting.

\section{Empiric Selection of Antimicrobials}

Table 2 summarizes the responses for attitudes toward empiric selection of antibiotics. Sixty-three percent of participants indicated that they base decisions upon the antibiogram in their setting while $56 \%$ indicated they start with broad spectrum and tailor antibiotic choices when culture results are received. The least common empiric decision making was asking others (physicians, other NPs, patient, etc.). Other open-ended comments included discuss with pharmacist, use evidence-based sources/guidelines and base therapy on cultures and past infection history. There was no significant correlation between years of NP experience and empiric selection of antimicrobials. There was also no significant difference in empiric selection of antimicrobials by NP degree or ethnicity. There was a statistically significant difference between type of NP setting and the decision to start with broad-spectrum antimicrobials $\left(X^{2}(10\right.$, 
$\mathrm{N}=193)=19.99, \mathrm{p}=.03$ ). NPs who worked in hospitals were more likely to report starting with broad spectrum and tailoring culture results than NPs who worked in private practice. There was also a difference between NP setting and asking an attending physician $\left(X^{2}(10, \mathrm{~N}=190)=33.39\right.$, $\mathrm{p}=.000)$. NPs in the hospital setting were more likely to ask an attending physician than NPs in the community or private practice setting.

\section{Perceptions About Antibiotic Use and Resistance}

Nurse practitioner perceptions about antibiotic use and resistance are summarized in Table 3. NPs reported understanding that inappropriate use of antibiotics causes resistance (97\%), harms the patient (97\%), and better antibiotic use will reduce resistance (94\%). Ninetyfour percent of respondents somewhat or strongly agreed that antibiotics are overused nationally. Participants indicated a strong knowledge of antibiotics was important for their job (94\%) and $86 \%$ felt confident in their use of antibiotics. Only $62 \%$ of NPs thought antibiotics were overused in their health care setting. Thirty-five percent agreed/strongly agreed other NPs overprescribe antibiotics. It is interesting to note that only $11 \%$ of participants believe that they overprescribed antibiotics.

In regards to interventions to improve antibiotic use, $77 \%$ of respondents would like more education on antibiotics. Seventy-five percent felt local guidelines would be more effective than national guidelines. The $67 \%$ of respondents would like more feedback on their antibiotic selections. There was no difference in perceptions about antibiotic use and resistance by NP degree or practice setting. However, there was a statistically significant difference between ethnicity and four of the perceptions about antimicrobials questions (Table 3). White participants were more likely to agree that interactions with pharmaceutical representatives did not influence their prescribing, that inappropriate antibiotics can cause harm and is unethical while non-white 
participants were more likely to agree that new antibiotics would be developed in the future to keep up with the resistance problem.

\section{Perceptions About Continuing Education Resources}

Perceptions about educational resources regarding antibiotics are summarized in Table 4. Continuing education online or live lectures (93\%), medical journals (85\%), and antimicrobial stewardship programs $(77 \%)$ were rated as the most useful sources for continuing education on antibiotics. The least helpful resources reported were pharmaceutical representatives (45\%), Google (43\%) and off-site, pharmaceutical company lectures (40\%). Open-ended responses included pharmacist, evidence-based guidelines and applications. There was no significant correlation between years of NP experience and perceptions about educational resources. There was no difference in NP setting and educational resources. There was a statistical difference in the helpfulness of education from pharmaceutical representatives, off-site lectures and Sanford Guide by degree. Participants with a Master's degree were more likely to report pharmaceutical representatives and off-site lectures as 'somewhat useless' than doctoral prepared participants did. Doctoral prepared participants were more likely to report the Sanford guide as 'somewhat useless' than Master's prepared participants did. There was a statistical difference in ethnicity and pharmaceutical representative, off-site lectures. White participants were more likely to report pharmaceutical representatives and off-site lectures as 'somewhat useless' than non-white participants did.

\section{Discussion}

The current ability to treat infections with antibiotics is being threatened by increasing antibiotic resistance. According to the World Health Organization (WHO, 2017), new antibiotics alone will not be enough to mitigate the threat of antibiotic resistance. Unless action is taken, 
common infections may become untreatable. ABS is one strategy to prevent the spread of antibiotic resistance. The most successful ABS interventions take place at the point of care, where NPs are positioned to make a difference.

\section{Decisions About Antibiotics}

Athena health looked at about 1.5 million primary care appointments between 2014 and 2017 to determine how NPs and MDs differed in their prescribing habits. These data revealed the network's NPs were $4.8 \%$ less likely than physicians to prescribe antibiotics inappropriately. The researchers suggested that the difference may be the NPs' background in health promotion and disease prevention. Taking time for patient education enables NPs and patients to work together as a team and allows NPs to manage patient expectations (Pereto, 2018).

Several factors influence NPs' choice of which antibiotic to prescribe. In this study, if the patient was critically ill or immunocompromised, 79\% of NPs indicated that this often/always influenced the decision to prescribe antibiotics. In the 2012 study of hospital NPs, $89 \%$ indicated the patient condition influenced their prescribing patterns (Abbo et al., 2012). This difference may be due to the higher acuity of patients seen in hospitals and that the population for this study was mostly community/private practice NPs.

Forty-four percent of NPs in this study were concerned about the risk of missing an infection compared to $67 \%$ in the 2012 study (Abbo et al., 2012). The $22 \%$ difference between the two studies may be due to the difference in patient populations. These findings and the response of NPs in this study that $62 \%$ never/rarely prescribe antibiotics for reassurance may also indicate that NPs now have more knowledge, more experience, or greater confidence.

The risk of developing Clostridium difficile colitis (C. difficile) was another big difference between the two studies. Respondents were asked 'how often does risk of developing 
Clostridium difficile colitis affect your decision to use antibiotics?" Twenty-six percent of the NPs in the Abbo et al., 2012 study reported that it often/always influenced their decision, while $58 \%$ of NPs in this study were concerned. A 2015 study by Lessa et al. may provide one possible reason for the increase. Each year in the United States, almost a half-million people are infected by $\mathrm{C}$. difficile. This infection rate amounts to about 15,000 deaths that are directly attributed to C. difficile infections. Since 2000 , there has been a dramatic increase in the number and severity of $C$. difficile infections. The reduction in antibiotic use may not only decrease resistance but decrease deaths associated with $C$. difficile. In a 2015 study, Dantes et al. estimated that reducing antibiotics by $10 \%$ could result in a 17-fold decrease in $C$. difficile (Dantes et al., 2015).

Cost of antibiotics is another influencing factor when prescribing. In our study, $30 \%$ of NPs often/always considered the cost to the health care setting compared to $59 \%$ of hospital NPs in 2012 (Abbo et al., 2012). Patient cost, however was much more of a consideration with 54\% reporting that patient cost often/always influenced their decision to prescribe antibiotics. Newer broad-spectrum antibiotics are often more expensive for both the patient and health care system. Giving feedback to providers about cost along with susceptibility testing data has been reported to decrease the number of prescriptions of high-cost antibiotics (Newman, Varkey, Rykowski, \& Mohan, 2015) and could help NPs concerned with cost.

Fifty-eight percent of NPs in this study indicated that patient demands and expectations for antibiotics never or rarely affected their decision to prescribe. This is somewhat different than the $78 \%$ of NPs in 2012 who reported that patient demands never/rarely affected their decision to prescribe antibiotics (Abbo, et al., 2012). Providers worried about patient expectations may be concerned that patients who leave the clinic without an antibiotic prescription may be less satisfied with the care they received. However, in a 2016 study, patient satisfaction was only 
slightly lower when patients did not receive antibiotics (Sharp, Shen, Kanter, Berman, \& Gould, 2016). Other factors such as patient age, multiple co-morbidities, and relationship with the provider had a stronger influence over patient satisfaction than an antibiotic prescription (Sharp et al., 2016). Patient satisfaction and demands for antibiotics are an important consideration because NPs may need to provide education for their patients. Gaarslev, Yee, Chan, FletcherLartey, \& Khan (2016) found that patients who knew antibiotics did not treat viral infections were less likely to demand antibiotics. This premise is supported by a study by O'Connor, O’Doherty, O'Regan \& Dunne (2018) who reported that multi-focused education interventions which included written communication along with increased provider time and communication skills were effective in reducing patient expectations.

\section{Empiric Selection of Antimicrobials}

In our study, $63 \%$ of respondents indicated that they often/always base their prescribing decisions on the antibiogram. These data are quite different from the Abbo et al. (2012) study in which only $29 \%$ of NPs reported they often/always used antibiograms. The findings in our study are somewhat interesting because in a study of hospital medical residents, $89 \%$ reported that they were aware of antibiograms but fewer (70\%) were comfortable using them and only $44 \%$ knew how to access an antibiogram (Tallman et al., 2018). Antibiograms are even less available in outpatient settings. In 2016, only $58 \%$ of Illinois pediatricians reported having access to an antibiogram (Spiekerman, Patel, Patel \& Kociolek, 2016).

\section{Perceptions About Antibiotic Use and Resistance}

Nurse practitioners recognize the problem of antibiotic resistance. In our study, $93 \%$ of NPs felt that improving use of antibiotics would reduce the risk of antibiotic resistance. The majority (94\%) of respondents felt that antibiotic resistance was a problem nationally and 63\% 
thought it is a problem in their health care setting. Similarly, 35.38\% of NPs felt that other NPs over-prescribe antibiotics, but only $11.40 \%$ thought that they did.

The majority of NPs (94\%) agreed that a strong knowledge of antibiotics is important in their career. Seventy-seven percent would like more education on antibiotics, and $67 \%$ would like feedback on their antibiotic selections. Education about antibiotics for patients as well as providers has shown to be effective in reducing antibiotic prescriptions (Spiekerman et al., 2016; Tallman et al., 2018).

\section{Perceptions About Continuing Education Resources}

Education is the cornerstone of ABS programs, but to make a difference education must be useful. Abbo et al. (2012) found that infectious disease colleagues (75\%), medical journals (71\%), and continuing education courses or live lectures $(60 \%)$ were the most useful resources. In this study, more participants rated continuing education online or live lectures (93\%) and medical journals ( $85 \%)$ as the most useful resources for continuing education on antibiotics. Seventy-seven percent also felt antimicrobial stewardship programs (77\%) were a useful resource. In ABS programs, 74\% somewhat or strongly agreed that locally developed guidelines for antibiotic treatment would be more useful than national guidelines. These findings are similar to those reported by Tallman et al. (2018) who indicated that hospital medical residents used UpToDate, online clinical decision support resource or The Sanford Guide to provide antibiotic prescribing information (Tallman et al., 2018).

\section{Limitations and Strengths}

This study is not without limitations. Potential study limitations include the low number of participants. The number of participants may have been related to location and the limits imposed by the AANP. Other possible limitations were that the participants were members of a 
professional organization and all attended the AANP National Conference. A final limitation was that the questionnaire was self-reported.

Study strengths included survey questions validated in previous studies and the variety of participants. The participants were not from a single institution but came from different backgrounds and practices environments across the nation.

\section{Conclusion}

Most NPs believe that antibiotic resistance is a problem and that antibiotics are overused nationally. Fewer NPs believe that it is a problem locally and fewer still that they contribute to the problem. Nurse Practitioners recognize that knowledge about antibiotics is important to their career and would like more education about antibiotics and feedback about their antibiotic choices. Finding effective means to provide this education and feedback could change practice and improve antibiotic use. 


\section{References}

Abbo, L., Smith, L., Pereyra, M., Wykoff, M., \& Hooton, T. M. (2012). Nurse practitioners' attitudes, perceptions, and knowledge about antimicrobial stewardship. The Journal of Nurse Practitioners, 8(5), 370-376. doi: 10.1016/j.nurpra.2012.01.023

Centers for Disease Control and Prevention. (2017). Antibiotic use in the United States, 2017: Progress and opportunities. Retrieved from https://www.cdc.gov/antibioticuse/stewardship-report/outpatient.htmlb

Dantes, R., Mu, Y., Hicks, L. A., Cohen, J., Bamberg, W., Beldavs, Z. G....Lessa, F. C. (2015). Association between outpatient antibiotic prescribing practices and communityassociated clostridium difficile infection. Open Forum Infectious Diseases, 2(3). doi: 10.1093/ofid/ofv113.

Gaarslev, C., Yee, M., Chan, G., Fletcher-Lartey, S., \& Khan, R. (2016). A mixed methods study to understand patient expectations for antibiotics for an upper respiratory tract infection. Antimicrobial Resistance and Infection Control, 5(39). doi: 10.1186/s13756-016-0134-3

IBM Corp. (2016). IBM SPSS Statistics for Windows, Version 24.0. Armonk, NY: IBM Corp.

Lessa, F., Mu, Y., Bamberg, W., Beldavs, Z., Dumyati, G., Dunn, J., .. McDonold, L. C. (2015). Burden of Clostridium difficile infection in the United States. New England Journal of Medicine, 372(9), 825-34. doi: 10.1056/NEJMoa1408913

Newman, K. L., Varkey, J., Rykowski, J., \& Mohan, A. V. (2015). Yelp for prescribers: A quasi-experimental study of providing antibiotic cost data and prescription of high-cost antibiotics in an academic and tertiary care hospital. Journal of General Internal Medicine, 30(8):1140-6. doi: 10.1007/s11606-015-3253-2. 
O'Connor, R., O’Doherty, J., O'Regan, A., \& Dunne, C. (2018). Antibiotic use for acute respiratory tract infections (ARTI) in primary care; what factors affect prescribing and why is it important? A narrative review. Irish Journal of Medical Science, 187(4), 969986. doi: 10.1007/s11845-018-1774-5.

O’Neill, J. (2016). Tackling drug-resistant infections globally: Final report and recommendations. Retrieved from https://amrreview.org/sites/default/files/160525_Final\%20paper_with\%20cover.pdf

Ohl, C., \& Luther, V. (2014). Health care provider education as a tool to enhance antibiotic stewardship practices. Infectious Disease Clinics of North America, 28(2), 177-193. doi:10.1016/j.idc.2014.02.001

Pereto, A. (2018). NPs less likely to prescribe unnecessary antibiotics. Retrieved from https://www.athenahealth.com/insight/nps-less-likely-prescribe-unnecessary-antibiotics

Qualtrics software, version May 2017. (2018). Provo, Utah USA. https://www.qualtrics.com

Sharp, A. L., Shen, E., Kanter, M. H., Berman, L. J., \& Gould, M. K. (2016). Low-value antibiotic prescribing and clinical factors influencing patient satisfaction. American Journal of Managed Care, 23(10), 589-594.

Spiekerman, K.M., Patel, S.J., Patel, R., \& Kociolek, L.K. (2016). Availability, perceptions, and characteristics of antibiograms among Illinois pediatricians. Infection and Drug Resistance, 5(9), 269-274.

Tallman, G.B., Vilches-Tran, R.A., Elman, M.R., Bearden, D.T., Taylor, J.E., Gorman, P.N. \& McGregor, J.C. (2018). Empiric antibiotic prescribing decisions among medical residents: The role of the antibiogram. Infection Control and Hospital Epidemiology, 39(5), 578-583. doi: 10.1017/ice.2018.28 
World Health Organization. (2017). Antibacterial agents in clinical development: An analysis of the antibacterial clinical development pipeline, including tuberculosis. Geneva: World Health Organization. 
Table 1

Attitudes That Might Influence NP Decision to Select an Antibiotic in General

\begin{tabular}{lrrrr}
\hline Consideration & $\begin{array}{c}\text { Never/ } \\
\text { Rarely }\end{array}$ & Sometimes & $\begin{array}{c}\text { Often/ } \\
\text { Always }\end{array}$ & $\mathrm{n}$ \\
\hline Patient is critically ill or immunocompromised & $6.12 \%$ & $14.80 \%$ & $79.08 \%$ & 196 \\
Risk of developing Clostridium difficile colitis & $17.50 \%$ & $25.00 \%$ & $57.50 \%$ & 200 \\
Cost savings for the patient & $21.50 \%$ & $24.50 \%$ & $54.00 \%$ & 200 \\
Risk of missing an infection & $23.74 \%$ & $31.82 \%$ & $44.45 \%$ & 198 \\
Cost savings for the health care system & $38.00 \%$ & $31.50 \%$ & $30.50 \%$ & 200 \\
Other & $50.00 \%$ & $26.92 \%$ & $23.08 \%$ & 26 \\
Unexplained fever or leukocytosis, even if & & & & \\
cultures are negative & $36.68 \%$ & $42.21 \%$ & $21.11 \%$ & 199 \\
Patient demands and expectations for antibiotics & $58.30 \%$ & $25.13 \%$ & $16.58 \%$ & 199 \\
Reassurance when using an antibiotic, even if it & & & & \\
might be the wrong one & $61.61 \%$ & $22.22 \%$ & $16.17 \%$ & 198 \\
Treat colonization to prevent infection & $63.13 \%$ & $24.24 \%$ & $12.63 \%$ & 198 \\
\hline
\end{tabular}


Table 2

NP Attitudes Toward the Empiric Selection of an Antibiotic in a Patient with No Culture Information

\begin{tabular}{lcccc}
\hline Response & $\begin{array}{c}\text { Never } \\
\text { /Rarely }\end{array}$ & Sometimes & $\begin{array}{c}\text { Often } \\
\text { /Always }\end{array}$ & $\mathrm{n}$ \\
\hline $\begin{array}{l}\text { I base my decisions on the antibiogram in my } \\
\text { health care setting. }\end{array}$ & $20.82 \%$ & $16.24 \%$ & $62.94 \%$ & 197 \\
I start with broad spectrum and tailor upon & $21.83 \%$ & $21.83 \%$ & $56.35 \%$ & 197 \\
culture results. & $55 \%$ & $10 \%$ & $35 \%$ & 20 \\
Other & $40.82 \%$ & $40.31 \%$ & $18.88 \%$ & 196 \\
I use the same 1 or 2 antibiotics. & $60.31 \%$ & $29.90 \%$ & $9.80 \%$ & 194 \\
I ask an attending physician. & $55.61 \%$ & $34.69 \%$ & $9.69 \%$ & 196 \\
I ask another NP or PA. & $70.41 \%$ & $23.47 \%$ & $6.12 \%$ & 196 \\
I ask the patient. & $93.30 \%$ & $6.19 \%$ & $0.52 \%$ & 194 \\
I ask a resident. & & &
\end{tabular}


Table 3

NP Perceptions About Antibiotic Use and Resistance

\begin{tabular}{|c|c|c|c|c|}
\hline Perceptions & $\begin{array}{l}\text { Disagree } \\
\text { Somewhat } \\
\text { or } \\
\text { Strongly } \\
\text { Disagree }\end{array}$ & Neutral & $\begin{array}{l}\text { Agree } \\
\text { Somewhat } \\
\text { or } \\
\text { Strongly } \\
\text { Agree }\end{array}$ & $\mathrm{n}$ \\
\hline $\begin{array}{l}\text { Inappropriate use of antibiotics causes } \\
\text { antimicrobial resistance. }\end{array}$ & $0.00 \%$ & $3.09 \%$ & $96.91 \%$ & 194 \\
\hline $\begin{array}{l}\text { Inappropriate use of antibiotics can harm } \\
\text { patients. }\end{array}$ & $0.52 \%$ & $2.62 \%$ & $96.86 \%$ & $191 *$ \\
\hline Antibiotics are overused nationally. & $4.57 \%$ & $1.02 \%$ & $94.41 \%$ & 197 \\
\hline $\begin{array}{l}\text { Strong knowledge of antibiotics is important in } \\
\text { my health care career. }\end{array}$ & $2.55 \%$ & $3.06 \%$ & $94.39 \%$ & 196 \\
\hline $\begin{array}{l}\text { Better use of antibiotics will reduce problems } \\
\text { with antimicrobial resistance. }\end{array}$ & $3.57 \%$ & $3.06 \%$ & $93.37 \%$ & 196 \\
\hline $\begin{array}{l}\text { I am concerned about antimicrobial resistance in } \\
\text { the community when I prescribe antibiotics. }\end{array}$ & $3.08 \%$ & $6.67 \%$ & $90.25 \%$ & 195 \\
\hline $\begin{array}{l}\text { I am confident that I use antibiotics optimally in } \\
\text { my health care setting. }\end{array}$ & $5.64 \%$ & $8.72 \%$ & $85.65 \%$ & 195 \\
\hline $\begin{array}{l}\text { I am concerned about antimicrobial resistance in } \\
\text { my health care setting when I prescribe } \\
\text { antibiotics. }\end{array}$ & $6.18 \%$ & $8.25 \%$ & $85.57 \%$ & 194 \\
\hline I would like more education on antibiotics. & $7.18 \%$ & $15.38 \%$ & $77.43 \%$ & 195 \\
\hline $\begin{array}{l}\text { Inappropriate use of antibiotics is professionally } \\
\text { unethical. }\end{array}$ & $5.19 \%$ & $17.62 \%$ & $77.21 \%$ & 193 \\
\hline $\begin{array}{l}\text { Prescribing broad-spectrum antibiotics when } \\
\text { equally effective narrower ones are available } \\
\text { increases antimicrobial resistance. }\end{array}$ & $12.88 \%$ & $10.82 \%$ & $76.29 \%$ & 194 \\
\hline $\begin{array}{l}\text { Locally developed guidelines for antibiotic } \\
\text { treatment would be more useful than national } \\
\text { ones. }\end{array}$ & $11.73 \%$ & $13.78 \%$ & $74.49 \%$ & $196^{*}$ \\
\hline $\begin{array}{l}\text { Poor infection control practices by health care } \\
\text { professionals' causes spread of antimicrobial } \\
\text { resistance. }\end{array}$ & $7.77 \%$ & $19.17 \%$ & $73.05 \%$ & 193 \\
\hline $\begin{array}{l}\text { Interactions with pharmaceutical representatives } \\
\text { do not influence my antibiotic selections. }\end{array}$ & $17.10 \%$ & $13.47 \%$ & $69.43 \%$ & $193 *$ \\
\hline $\begin{array}{l}\text { I would like more feedback on my antibiotic } \\
\text { selections. }\end{array}$ & $11.29 \%$ & $22.05 \%$ & $66.67 \%$ & 195 \\
\hline $\begin{array}{l}\text { Antibiotics are overused in my health care } \\
\text { setting. }\end{array}$ & $21.43 \%$ & $16.33 \%$ & $62.25 \%$ & 196 \\
\hline $\begin{array}{l}\text { I am less likely to use restricted antibiotics if } \\
\text { infectious disease approval is required. }\end{array}$ & $18.56 \%$ & $25.26 \%$ & $56.19 \%$ & $194^{*}$ \\
\hline
\end{tabular}


Other NPs over-prescribe antibiotics.

$21.03 \%$

$43.59 \% \quad 35.38 \%$

195

Antibiotic management programs are an obstacle to good patient care.

$58.46 \% \quad 18.97 \% \quad 22.57 \% \quad 195$

New antibiotics will be developed in the future

that will keep up with the problem of

$58.76 \% \quad 20.10 \% \quad 21.13 \% \quad 194$

"resistance."

Antibiotic resistance is not a significant problem

in my health care setting.

$63.26 \% \quad 17.35 \% \quad 19.39 \% \quad 196$

I over-prescribe antibiotics.

$71.50 \% \quad 17.10 \% \quad 11.40 \% \quad 193$

Antibiotic resistance is not a significant problem nationally.

$89.23 \% \quad 0.00 \% \quad 10.77 \% \quad 195$

$* \mathrm{P}<.05$ difference in responses by ethnicity 
Table 4

Frequency Distribution of NPs Perception Toward Various Educational Resources as a Source for Continuous Education on Antibiotics

\begin{tabular}{|c|c|c|c|c|}
\hline Resource & $\begin{array}{c}\text { Somewhat } \\
\text { Useful or } \\
\text { Useful } \\
\end{array}$ & $\begin{array}{c}\text { Somewhat } \\
\text { Useless or } \\
\text { Useless }\end{array}$ & NA & $\mathrm{n}$ \\
\hline CE online or live lectures & $92.71 \%$ & $2.08 \%$ & $5.21 \%$ & 96 \\
\hline Medical journals & $84.69 \%$ & $9.18 \%$ & $6.12 \%$ & 98 \\
\hline Antimicrobial Stewardship Program & $76.84 \%$ & $6.48 \%$ & $13.68 \%$ & 95 \\
\hline UpToDate & $69.23 \%$ & $9.23 \%$ & $21.54 \%$ & 65 \\
\hline Sanford Guide & $68.60 \%$ & $8.14 \%$ & $23.26 \%$ & $86^{@}$ \\
\hline Grand Rounds/Staff Meetings & $66.66 \%$ & $10.32 \%$ & $23.02 \%$ & 126 \\
\hline $\begin{array}{l}\text { Infectious diseases colleagues } \\
\text { (fellows or faculty) }\end{array}$ & $66.29 \%$ & $2.24 \%$ & $31.46 \%$ & 89 \\
\hline Internet Web sites & $49.40 \%$ & $38.10 \%$ & $12.50 \%$ & 168 \\
\hline Unit/Clinic Rotations & $48.98 \%$ & $23.13 \%$ & $27.89 \%$ & 147 \\
\hline $\begin{array}{l}\text { Off-site lecture sponsored by } \\
\text { pharmaceutical company }\end{array}$ & $47.34 \%$ & $40.24 \%$ & $12.43 \%$ & $169 * @$ \\
\hline Google & $46.70 \%$ & $43.11 \%$ & $10.18 \%$ & 167 \\
\hline Pharmaceutical representatives & $45.67 \%$ & $44.77 \%$ & $11.56 \%$ & $173 * @$ \\
\hline Other & $17.86 \%$ & $7.14 \%$ & $75.00 \%$ & 28 \\
\hline
\end{tabular}

${ }^{*} \mathrm{p}<.05$ difference in responses by ethnicity

(a) $\mathrm{p}<.05$ difference in responses by degree 
Appendix

\section{Survey Instrument}

1. The following are factors that may influence a NPs decision to use antibiotics. Please indicate how often these aspects affect your decisions.

\begin{tabular}{|c|c|c|c|c|c|}
\hline & Never & Rarely & Sometimes & Often & Always \\
\hline a. Cost savings for the patient & & & & & \\
\hline b. Cost savings for the health care setting & & & & & \\
\hline c. Risk of missing an infection & & & & & \\
\hline d. Patient demands and expectations for antibiotics & & & & & \\
\hline e. Patient is critically ill or immunocompromised & & & & & \\
\hline $\begin{array}{l}\text { f. Reassurance when using an antibiotic, even if it } \\
\text { might be the wrong one }\end{array}$ & & & & & \\
\hline $\begin{array}{l}\text { g. Unexplained fever or leukocytosis, even if } \\
\text { cultures are negative }\end{array}$ & & & & & \\
\hline h. Treat colonization to prevent infection & & & & & \\
\hline i. Risk of developing Clostridium difficile colitis & & & & & \\
\hline j. Other: Please Describe & & & & & \\
\hline
\end{tabular}

2. The following are attitudes toward empiric selection of an antibiotic in a patient with no culture information. Please indicate how often you make the decision provided.

\begin{tabular}{|c|c|c|c|c|c|c|}
\hline & Never & Rarely & Sometimes & Often & Always & $\begin{array}{c}\text { Does } \\
\text { not } \\
\text { apply }\end{array}$ \\
\hline $\begin{array}{l}\text { a. I start with broad spectr } \\
\text { upon culture results. }\end{array}$ & & & & & & \\
\hline $\begin{array}{l}\text { b. I base my decisions on } \\
\text { in my health care settin }\end{array}$ & & & & & & \\
\hline c. I ask a resident. & & & & & & \\
\hline d. I ask an attending physi & & & & & & \\
\hline e. I ask another NP or PA. & & & & & & \\
\hline f. I use the same 1 or 2 an & & & & & & \\
\hline g. I ask the patient. & & & & & & \\
\hline h. Other: Please describe & & & & & & \\
\hline
\end{tabular}


3. Indicate your level of agreement with the following statements about antibiotic use and resistance:

\begin{tabular}{|c|c|c|c|c|c|}
\hline & \multicolumn{3}{|c|}{$\begin{array}{l}\text { Strongly } \\
\text { Disagree }\end{array}$} & \multicolumn{2}{|c|}{$\begin{array}{r}\text { Strongly } \\
\text { Agree }\end{array}$} \\
\hline & 1 & 2 & 3 & 4 & 5 \\
\hline a. Antibiotics are overused nationally. & & & & & \\
\hline b. Antibiotics are overused in my health care setting. & & & & & \\
\hline $\begin{array}{l}\text { c. Antibiotic resistance is a not significant problem } \\
\text { nationally. }\end{array}$ & & & & & \\
\hline $\begin{array}{l}\text { d. Antibiotic resistance is not a significant problem in } \boldsymbol{m} \\
\text { health care setting. }\end{array}$ & & & & & \\
\hline $\begin{array}{l}\text { e. Better use of antibiotics will reduce problems with } \\
\text { antimicrobial resistance. }\end{array}$ & & & & & \\
\hline $\begin{array}{l}\text { f. Strong knowledge of antibiotics is important in } \boldsymbol{m y} \\
\text { health care career. }\end{array}$ & & & & & \\
\hline $\begin{array}{l}\text { g. I am confident that I use antibiotics optimally in } \boldsymbol{m y} \\
\text { health care setting. }\end{array}$ & & & & & \\
\hline h. I overprescribe antibiotics. & & & & & \\
\hline i. Other NPs overprescribe antibiotics. & & & & & \\
\hline $\begin{array}{l}\text { j. Antibiotic management programs are an obstacle to } \\
\text { good patient care. }\end{array}$ & & & & & \\
\hline $\begin{array}{l}\text { k. I would like more feedback on my antibiotic } \\
\text { selections. }\end{array}$ & & & & & \\
\hline 1. I would like more education on antibiotics. & & & & & \\
\hline $\begin{array}{l}\text { m. I am less likely to use restricted antibiotics if } \\
\text { infectious disease approval is required. }\end{array}$ & & & & & \\
\hline $\begin{array}{l}\text { n. Interactions with pharmaceutical representatives do } \\
\text { not influence my antibiotic selections. }\end{array}$ & & & & & \\
\hline $\begin{array}{l}\text { o. Locally developed guidelines for antibiotic treatment } \\
\text { would be more useful than national ones. }\end{array}$ & & & & & \\
\hline $\begin{array}{l}\text { p. I am concerned about antimicrobial resistance in the } \\
\text { community when I prescribe antibiotics. }\end{array}$ & & & & & \\
\hline $\begin{array}{l}\text { q. I am concerned about antimicrobial resistance in my } \\
\text { health care setting when I prescribe antibiotics. }\end{array}$ & & & & & \\
\hline $\begin{array}{l}\text { r. New antibiotics will be developed in the future that } \\
\text { will keep up with the problem of "resistance." }\end{array}$ & & & & & \\
\hline $\begin{array}{l}\text { s. Prescribing broad-spectrum antibiotics when equally } \\
\text { effective narrower ones are available increases } \\
\text { antimicrobial resistance. }\end{array}$ & & & & & \\
\hline
\end{tabular}




\begin{tabular}{|c|c|c|c|c|c|}
\hline & \multicolumn{3}{|c|}{$\begin{array}{l}\text { Strongly } \\
\text { Disagree }\end{array}$} & \multicolumn{2}{|c|}{$\begin{array}{r}\text { Strongly } \\
\text { Agree }\end{array}$} \\
\hline & 1 & 2 & 3 & 4 & 5 \\
\hline $\begin{array}{l}\text { t. Poor infection control practices by health care } \\
\text { professionals' causes spread of antimicrobial } \\
\text { resistance. }\end{array}$ & & & & & \\
\hline $\begin{array}{l}\text { u. Inappropriate use of antibiotics causes antimicro } \\
\text { resistance. }\end{array}$ & & & & & \\
\hline v. Inappropriate use of antibiotics can harm patient & & & & & \\
\hline $\begin{array}{l}\text { w. Inappropriate use of antibiotics is professionally } \\
\text { unethical. }\end{array}$ & & & & & \\
\hline
\end{tabular}


4. The following are educational resources for continuous education on antibiotics. Please indicate how helpful you think these resources would be to you as you prescribe antibiotics.

\begin{tabular}{|c|c|c|c|c|c|c|}
\hline & $\begin{array}{l}\text { Never } \\
\text { Useful }\end{array}$ & & & & $\begin{array}{c}\text { Very } \\
\text { Useful }\end{array}$ & $\begin{array}{c}\text { Not } \\
\text { Applicable }\end{array}$ \\
\hline & 1 & 2 & 3 & 4 & 5 & \\
\hline $\begin{array}{l}\text { a. Antimicrobial Stewardsh } \\
\text { Program }\end{array}$ & & & & & & \\
\hline b. Unit/Clinic rotations & & & & & & \\
\hline c. Grand rounds/Staff Mee & & & & & & \\
\hline $\begin{array}{l}\text { d. Infectious diseases colle } \\
\text { (fellows or faculty) }\end{array}$ & & & & & & \\
\hline e. Pharmaceutical represen & & & & & & \\
\hline $\begin{array}{l}\text { f. Off-site lecture sponsore } \\
\text { pharmaceutical company }\end{array}$ & & & & & & \\
\hline g. CE online or live lecture & & & & & & \\
\hline h. Medical journals & & & & & & \\
\hline i. Sanford Guide & & & & & & \\
\hline j. UptoDate & & & & & & \\
\hline k. Google & & & & & & \\
\hline 1. Internet Web sites & & & & & & \\
\hline m. Other: Please Describe & & & & & & \\
\hline
\end{tabular}




\section{About You:}

1. How many years have you been a Nurse Practitioner?

2. How would you classify the population for your initial nurse practitioner education?

Adult Acute Care NP

Adult Gerontology Primary Care NP

Adult Gerontology Acute Care NP

Adult Psychiatric \& Mental Health NP

Family NP

Gerontology NP $\square$ Neonatal NP Adult NP

$\square$ Pediatric Acute Care NP

$\square$ Pediatric Primary Care NP

Psychiatric-Mental Health NP - Across the Lifespan

$\square$ Women's Health NP

$\square$ Other: Please describe

3. Please indicate your NP degree:

$\square$ Master's $\square$ Post Master's $\square$ Post-BS Doctor of Nursing $\square$ Post-MS Doctor of Nursing $\square$ Other: Please describe

4. What is your gender? $\square$ Male $\square$ Female $\square$ Other

5. Please specify your ethnicity:

$\square$ White $\square$ Hispanic or Latino $\square$ Black or African American $\square$ Native American or American Indian $\square$ Asian / Pacific Islander $\square$ Other

6. Which of the following best describes your health care setting? (Check all that apply)

Community Clinic

Emergency department

$\square$ Health Department

Health Maintenance Organization

Home Health Care Agency

Hospital

Long-term Care

$\square$ Nurse-managed medical center

$\square$ Other: Please describe 